ORIGINAL ARTICLE

\title{
Comparison between Total Intravenous Anesthesia Using Propofol and Inhalational Anesthesia Using Isoflurane on the Quality of Surgical Field in Spine Surgery
}

\author{
Ahmed Abdelkhalik Abdullah , Samia Mohammed Masoud, Howaida Kamal Abdellatif , \\ Olfat Abdelmonem Ibrahem \\ Anesthesia and Surgical Intensive Care Department, Faculty of Medicine, Zagazig University, \\ Zagazig , Egypt
}

Corresponding Author:

Ahmed Abdelkhalik Abdullah Elassar.

Anesthesia and Surgical Intensive Care

Department, Faculty of Medicine, Zagazig

University, Zagazig ,

Egypt

E-mail:

ahmedabdelkhalik71022@yahoo. $\underline{\text { com }}$

\begin{abstract}
Background: Spinal surgery in adults can vary from simple to complex and can also have variable anticipated surgical blood loss. There are several factors that can put patients at increased risk for greater intraoperative blood loss. This study aimed to compare between total intra venous anesthesia (with propofol) and inhalational anesthesia (with isoflurane) on the quality of surgical field in spine surgery.

Patients \& Methods: A prospective comparative randomized clinical study for comparison between total intra venous anesthesia (with propofol) and inhalational anesthesia (with isoflurane) on the quality of surgical field and hemodynamics of patients in spine surgery. Thirty patients in the age group of 21-50 years with ASA physical status Classes I and II, undergoing spine surgery were randomly divided into two equal groups of fiften each. In Group S: received isoflurane-based inhalational anesthesia and in Group P: were administered TIVA with propofol. All patients in both groups were assessed for: hemodynamics (heart rate,mean arterial blood pressure), respiratory profile ( $\mathrm{SpO} 2 \%$, end tidal $\mathrm{CO} 2$ ), surgical field rating scale, surgeon satisfaction, total blood lost and amount of transfused blood during surgery.

Results: Regarding mean blood pressure, it was less in group $\mathrm{P}$ than group S. Regarding heart rate values, it was less in group $\mathrm{P}$ than group $\mathrm{S}$.Regarding total blood loss, it was more in group S .Group P had better surgical field rating than group $\mathrm{S}$. The surgeon operating on the group receiving propofol had better satisfaction. There were no significant differences between the studied groups regarding ETCO2 and $\mathrm{SpO} 2$ over time.

Conclusion: In spine surgery, using TIVA with propofol provides better hypotensive anesthesia, decreases blood loss during surgery and also provides good quality of surgical field as compared to using inhalational anesthesia with isoflurane.
\end{abstract}

Keywords: Spine surgery, Surgical field, Isoflurane, Propofol, Total intravenous anesthesia.

\section{INTRODUCTION}

Apinal surgery in adults can vary from simple to complex and can also have variable anticipated surgical blood loss ${ }^{[1]}$.

General anesthesia is used to minimize bleeding by lowering intraoperative blood pressure. [2]. Hypotensive anesthesia has three potential benefits:1) reduced blood loss with a consequent reduction in risks associated with blood transfusion;2) improved quality (dryness) of the operative field, potentially allowing more accurate dissection and improved surgical results;and 3) reduced operative time ${ }^{[3]}$.

When formulating an anesthetic plan,the anesthesiologist deliberates over numerous therapeutic decisions.Perhaps chief among these is whether to proceed with an inhalation or intravenous anesthetic technique [4]. 
Propofol (2,6-diisopropylphenol) is the most commonly used intravenous agent for induction of anesthesia. Its success in the clinical setting has been a result of its rapid onset ,short duration of action, and minimal side effects despite the disadvantages associated with its oil emulsion formulation [5].

Isoflurane is an inhalational anesthetics whose low solubility (blood/gas partition coefficient equals 1.4) permits a rapid induction of and recovery from anesthesia.The mild pungency of isoflurane may limit the rate of induction.although excessive salivation or tracheobronchial secretions do not appear to be stimulated. The level of anesthesia may be changed rapidly with isoflurane ${ }^{[6]}$.

Thus, it is of interest whether moderate controlled hypotension can increase the intraoperative visibility without the side effects encountered with severe hypotension. This study aimed to assess the hemodynamic characteristics and quality of surgical field in spine surgery ,comparing total intravenous anesthesia (with propofol) and inhalational anesthesia (with isoflurane).

\section{PATIENTS \& METHODS}

After obtaining approval from the scientific committee of anesthesia and surgical intensive care department and the institutional review board (IRB) of faculty of medicine Zagazig University. Written informed consent was obtained from all participants. The work has been carried out in accordance with The Code of Ethics of the World Medical Association (Declaration of Helsinki) for studies involving humans.

This Prospective comparative randomized clinical study was carried out in orthopedic and neurosurgical operating rooms of Zagazig university hospitals from January 2018 to Augustus 2018.

Thirty patients were included divided into 2 groups 15 patients in each group: In Group S, maintainence of anesthesia done with oxygen $100 \%$ and isoflurane was adjusted according to mean blood pressure not exceed two minimum alveolar concentration (MAC of isoflurane is $1.15 \%$ )

and In Group P, maintainence done with oxygen $100 \%$ and propofol infusion at 12 $\mathrm{mg} / \mathrm{kg} / \mathrm{hr}$ for $10 \mathrm{~min}$, then $10 \mathrm{mg} / \mathrm{kg} / \mathrm{hr}$ for next $10 \mathrm{~min}$ and continued at $8 \mathrm{mg} / \mathrm{kg} / \mathrm{hr}$ for the remaining time of surgery.

Inclusion criteria: Age: 21-50 years old, Gender: males and females, Physical status: ASA $1 \&$ II and BMI $<35 \mathrm{~kg} / \mathrm{m} 2$. Exclusion criteria: Patients with morbid obesity, with known allergy to study drugs, suffering from severe chronic (cardiac, renal, hepatic and neurological diseases),suffering from uncontrolled hypertension, refusing the technique, on anticoagulant therapy, mentally retarded and who have previous spine surgery.

All patients were visited a day before the surgery and explained in detail the anesthetic procedure, informed and written consent was obtained. All patients were kept nil orally before the operation $(8 \mathrm{~h}$ for fatty meal, $6 \mathrm{~h}$ for light meal and $2 \mathrm{~h}$ for clear fluids).

On arrival to the operating room, standard monitors were attached. Parameters such as pulse rate, blood pressure (BP), respiratory rate, and oxygen saturation (SpO2) were recorded as a baseline reading (5 minutes preoperative). Intravenous line was inserted and midazolam $(0.02-0.05 \mathrm{mg} / \mathrm{kg})$ was given.

Preoxygenation with $100 \%$ oxygen for $3 \mathrm{~min}$ was done. Induction of anesthesia was done with fentanyl $(2 \mu \mathrm{g} . / \mathrm{kg})$, and propofol $(2 \mathrm{mg} / \mathrm{kg})$. After ensuring adequate ventilation, injection of atracurium (0.5 $\mathrm{mg} / \mathrm{kg}$ ) was administered to facilitate orotracheal intubation. Immediately after intubation, the patient was connected to mechanical ventilation (TV $7 \mathrm{ml} / \mathrm{kg}$, RR 14 /min, I:E ratio 1:2.5), ventilator parameters were adjusted to keep ETCO2 $35-40 \mathrm{mmHg}$ and vital parameters were recorded [HR, arterial blood pressure by non invasive method, SPO2, ETCO2].

After intubation, maintenance of anesthesia was done with $100 \%$ oxygen and isoflurane up to two minimum alveolar concentration( MAC of isoflurane is $1.15 \%$ ) in Group S. In Group P, maintenance was done with $100 \%$ oxygen and propofol infusion at $12 \mathrm{mg} / \mathrm{kg} / \mathrm{hfor} 10 \mathrm{~min}$, then 10 $\mathrm{mg} / \mathrm{kg} / \mathrm{h}$ for next $10 \mathrm{~min}$ and continued at 8 $\mathrm{mg} / \mathrm{kg} / \mathrm{h}$. The target in both groups was to 
achieve amean arterial BP of $60-65 \mathrm{mmHg}$. The total dose of propofol given was calculated. Neuromuscular blockade was provided with injection of atracurium (0.1 $\mathrm{mg} / \mathrm{kg} / 20 \mathrm{~min}$ ).

All vital signs were recorded before induction of anesthesia (baseline readings), post induction of anesthesia, post positioning of patient and after skin incision then every 5 min for $15 \mathrm{~min}$ and then every $10 \mathrm{~min}$ till the end of surgery. Surgeon's opinion was also recorded regarding the quality of surgical field.

The quality of surgical field was evaluated every $15 \mathrm{~min}$ using the surgical field rating (SFR) scale of six points proposed by Fromme et al. ${ }^{[7]}$ : 5 - massive uncontrollable bleeding, 4 - heavy but controllable bleeding that significantly interfered with dissection, 3 - moderate bleeding that moderately compromised surgical dissection, 2 - moderate bleeding - a nuisance but without interference with accurate dissection, 1 - bleeding, so mild it was not even a surgical nuisance, 0 - no bleeding and virtually bloodless field. Surgical field was graded as good, fair, and poor as: good - SFR scale 0 or 1 , fair - SFR scale 2or 3, poor - SFR scale 4 or 5 .

Intraoperative bleeding was measured by collecting blood in a marked container of $2500 \mathrm{ml}$ capacity and the blood soaked by gauze pieces $[4 \times 4$ soaked gauze piece $(15 \mathrm{ml}$ blood), completely soaked abdominal towel (150 ml blood) ]. Intraoperative side effects (such as hypotension or hypertension, bradycardia or tachycardia and bleeding) or postoperative side effects were recorded and managed. If mean blood pressure became less than $50 \mathrm{mmHg}$, propofol titrated or isoflurane dose adjusted. If bradycardia developed (HR less than $20 \%$ of basal HR), atropine $1 \mathrm{mg}$ was given.

Statistical analysis: Assuming mean and standard deviation of time to achieve target blood pressure in patients using isoflurane and in those using propofol is $(18 \pm 2$ vs $16 \pm 1.9$ respectively), so sample size was calculated to be 30 patients ,15 in each group using Open Epi program with confidence level $95 \%$, power of test $80 \%$. Calculated sample size was according to Saravanan et al. [8]. Data analysis was performed using the software SPSS (Statistical Package for the Social Sciences) version 20. Quantitative variables were described using their means and standard deviations. Categorical variables were described using their absolute frequencies and to compare the proportion of categorical data, chi square test and fisher exact test were used when appropriate. Kolmogorov-Smirnov (distribution-type) and Levene (homogeneity of variances) tests were used to verify assumptions for use in parametric tests. To compare means of two groups, independent sample $t$ test was used when appropriate. Nonparametric test (Mann Whitney) was used to compare means when data was not normally distributed and to compare medians in categorical data. To compare change over time in hemodynamic parameters in each group, repeated measure ANOVA was used. The level statistical significance was set at $5 \%(P<0.05)$. Highly significant difference was present if $\mathrm{p} \leq 0.001$.Data were collected, tabulated and submitted to statistical analysis.

\section{RESULTS}

The characteristics of patients (in terms of age, weight, BMI and ASA grading) and type of surgery were found to be statistically non-significant between two groups (Table 1).

There was statistically significant difference between the studied propofol and isoflurane groups regarding total blood loss, more in isoflurane group $(177.15 \pm 20.79) \mathrm{ml}$ than propofol group $(152.25 \pm 29.11) \mathrm{ml}(\mathrm{P}<$ 0.05) (Table 2).

There was statistically significant difference between the studied propofol and isoflurane groups regarding surgical field rating at $15,30,45,60,75,90$ minutes, propofol group had better surgical field rating than isoflurane group (Figure 1).

There were highly statistically significant differences between the studied propofol and isoflurane groups regarding mean blood pressure as it less in propofol group than isoflurane group at 5, 10, 15, 25, 55 minutes (Figure 2).

There were significant differences between the studied propofol and isoflurane 
groups regarding heart rate values as it less in and 55minutes (Figure 3).

propofol group than isoflurane group at 35,45

Table (1): demographic data of studied groups

\begin{tabular}{|c|c|c|c|c|}
\hline & Group P & Group S & $t$ test & $\mathbf{P}$ \\
\hline $\begin{array}{l}\text { Age (year): } \\
\text { Mean } \pm \text { SD } \\
\text { Range }\end{array}$ & $\begin{array}{l}\mathbf{3 7 . 5 3} \pm 9.66 \\
\mathbf{2 0}-\mathbf{4 8}\end{array}$ & $\begin{array}{l}\mathbf{3 7 . 9 3} \pm 8.36 \\
\mathbf{2 2}-\mathbf{4 8}\end{array}$ & -0.121 & 0.904 \\
\hline $\begin{array}{l}\text { Gender: } \\
\text { Male } \\
\text { Female }\end{array}$ & $\begin{array}{l}7(46.7 \%) \\
8(53.3 \%)\end{array}$ & $\begin{array}{l}7(46.7 \%) \\
8(53.3 \%)\end{array}$ & & \\
\hline $\begin{array}{l}\text { ASA } \\
\text { I } \\
\text { II }\end{array}$ & $\begin{array}{l}12 \\
3\end{array}$ & $\begin{array}{l}11 \\
4\end{array}$ & $\begin{array}{l}\text { MW (- } \\
1.466)\end{array}$ & 0.143 \\
\hline $\begin{array}{l}\text { BMI }(\mathrm{Kg} / \mathrm{m} 2): \\
\text { Mean } \pm \text { SD } \\
\text { Range }\end{array}$ & $\begin{array}{l}25.2 \pm 2.73 \\
20-30\end{array}$ & $\begin{array}{l}23.87 \pm 2.75 \\
20-30\end{array}$ & 1.333 & 0.193 \\
\hline
\end{tabular}

Group P: propofol group

Group S: isoflurane group

Data were expressed as mean \pm Standard deviation $(\mathrm{SD})$ and range

$\mathrm{t}$ : independent sample $\mathrm{t}$ test

MW: Mann Whitney test

$\mathrm{P}>0.05$ is non significant

Table (2): operative data of studied groups

\begin{tabular}{|c|c|c|c|c|}
\hline (2) & Group P & Group S & $\mathrm{X} 2$ & $\mathbf{P}$ \\
\hline $\begin{array}{l}\text { Type of operation: } \\
\text { Discectomy } \\
\text { Laminectomy }\end{array}$ & $\begin{array}{l}7(46.7) \\
8(53.3)\end{array}$ & $\begin{array}{l}8(53.3) \\
7(46.7)\end{array}$ & 0.133 & 0.715 \\
\hline & Group P & Group S & t test & \\
\hline $\begin{array}{l}\text { Duration of surgery }(\mathrm{min}): \\
\text { Mean } \pm \text { SD } \\
\text { Range }\end{array}$ & $\begin{array}{c}82 \pm 21.11 \\
60-120\end{array}$ & $\begin{array}{c}79 \pm 18.34 \\
60-120\end{array}$ & 0.415 & 0.681 \\
\hline $\begin{array}{l}\text { Total IV fluid (ml): } \\
\text { Mean } \pm \text { SD } \\
\text { Range }\end{array}$ & $\begin{array}{c}1166.67 \pm 187.72 \\
900-1500\end{array}$ & $\begin{array}{c}1136.67 \pm 146.95 \\
800-1300\end{array}$ & 0.487 & 0.630 \\
\hline $\begin{array}{l}\text { Total blood lost }(\mathrm{ml}): \\
\text { Mean } \pm \text { SD } \\
\text { Range }\end{array}$ & $\begin{array}{c}152.25 \pm 29.11 \\
112-225\end{array}$ & $\begin{array}{c}177.15 \pm 20.79 \\
135-225\end{array}$ & -2.696 & $0.012 *$ \\
\hline $\begin{array}{l}\text { Total amount of propofol }(\mathrm{mg}): \\
\text { Mean } \pm \text { SD } \\
\text { Range }\end{array}$ & $\begin{array}{c}1326.67 \pm 96.12 \\
1200-1500 \\
\end{array}$ & & & \\
\hline $\begin{array}{l}\text { Total amount of Isoflurane }(\mathrm{ml}): \\
\text { Mean } \pm \text { SD } \\
\text { Range }\end{array}$ & & $\begin{array}{c}57.26 \pm 8.3 \\
50-70 \\
\end{array}$ & & \\
\hline $\begin{array}{l}\text { Mean of Isoflurane end tidal } \\
\text { concentration }(\%) \text { : } \\
\text { Mean } \pm \text { SD } \\
\text { Range }\end{array}$ & & $\begin{array}{c}2.18 \pm 0.41 \\
1.7-3 \\
\end{array}$ & & \\
\hline
\end{tabular}

Group P: propofol group Group S: isoflurane group

Data were expressed as mean \pm Standard deviation (SD) and range

$\mathrm{X}^{2}$ : chi square test $\mathrm{t}$ : independent sample $\mathrm{t}$ test

$* \mathrm{p}<0.05$ is statistically significant 


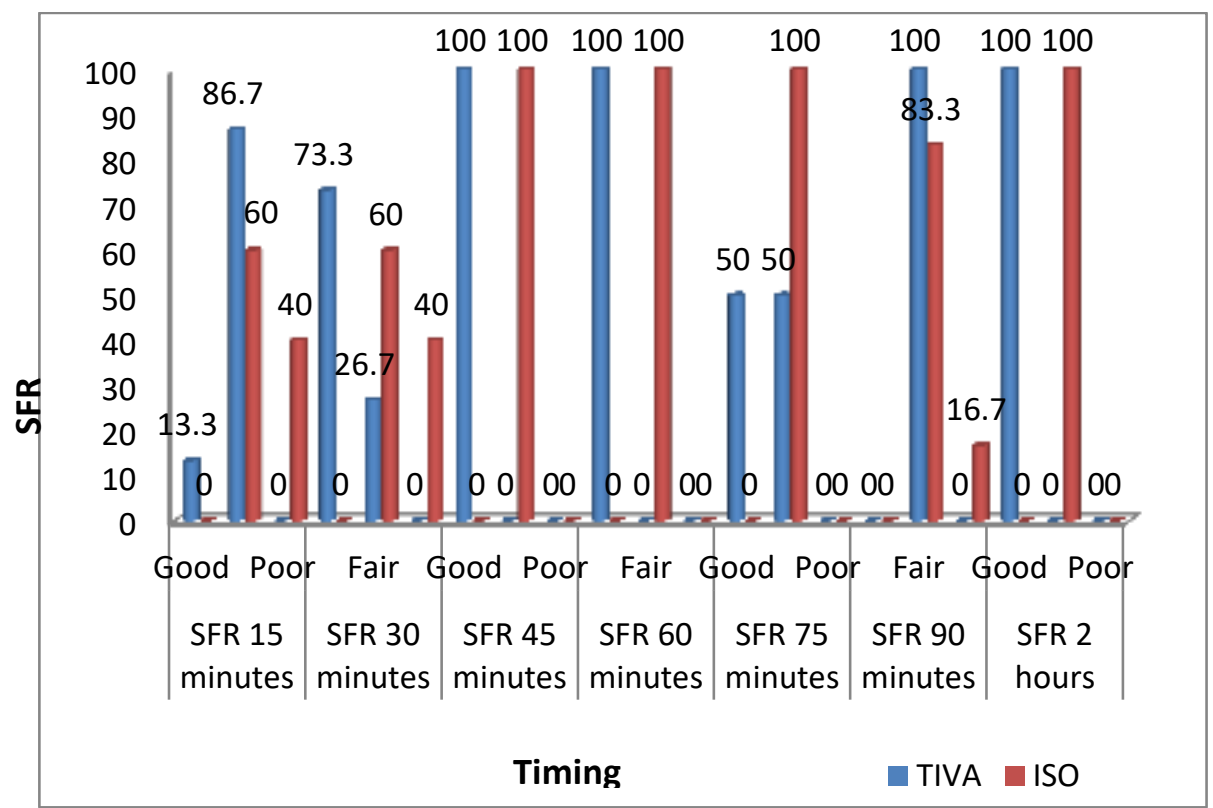

Figure 1. Showing surgical field rating (SFR) scale of studied groups over time

TIVA group: total intravenous anesthesia using propofol

Iso group: isoflurane group

$\mathrm{X}^{2}$ : chi square test

$\mathrm{p}<0.05$ is statistically significant

$\mathrm{p} \leq 0.001$ is highly significant

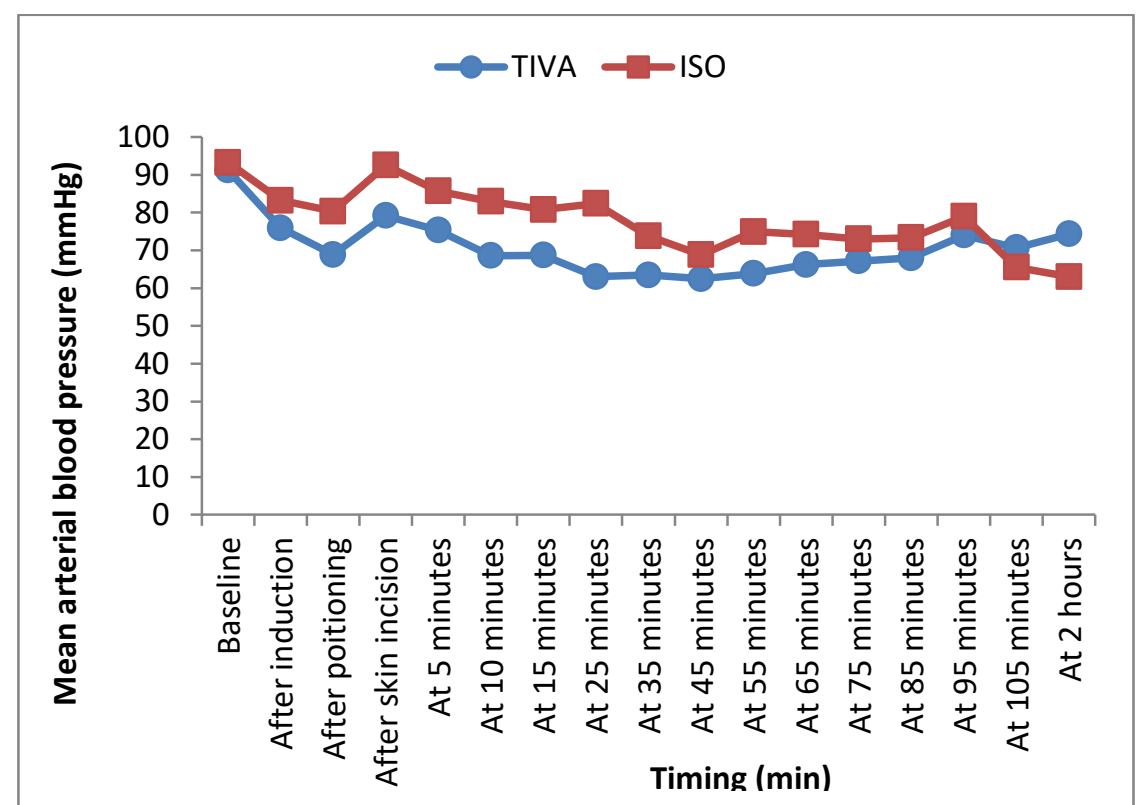

Figure 2. Showing change in mean blood pressure (mmHg) among studied groups over the scheduled time.

TIVA group: total intravenous anesthesia using propofol

Iso group: isoflurane group

Data were expressed as mean \pm Standard deviation (SD)

$\mathrm{t}$ : independent sample $\mathrm{t}$ test

$\mathrm{p}<0.05$ is statistically significant

$\mathrm{p} \leq 0.001$ is highly significant 


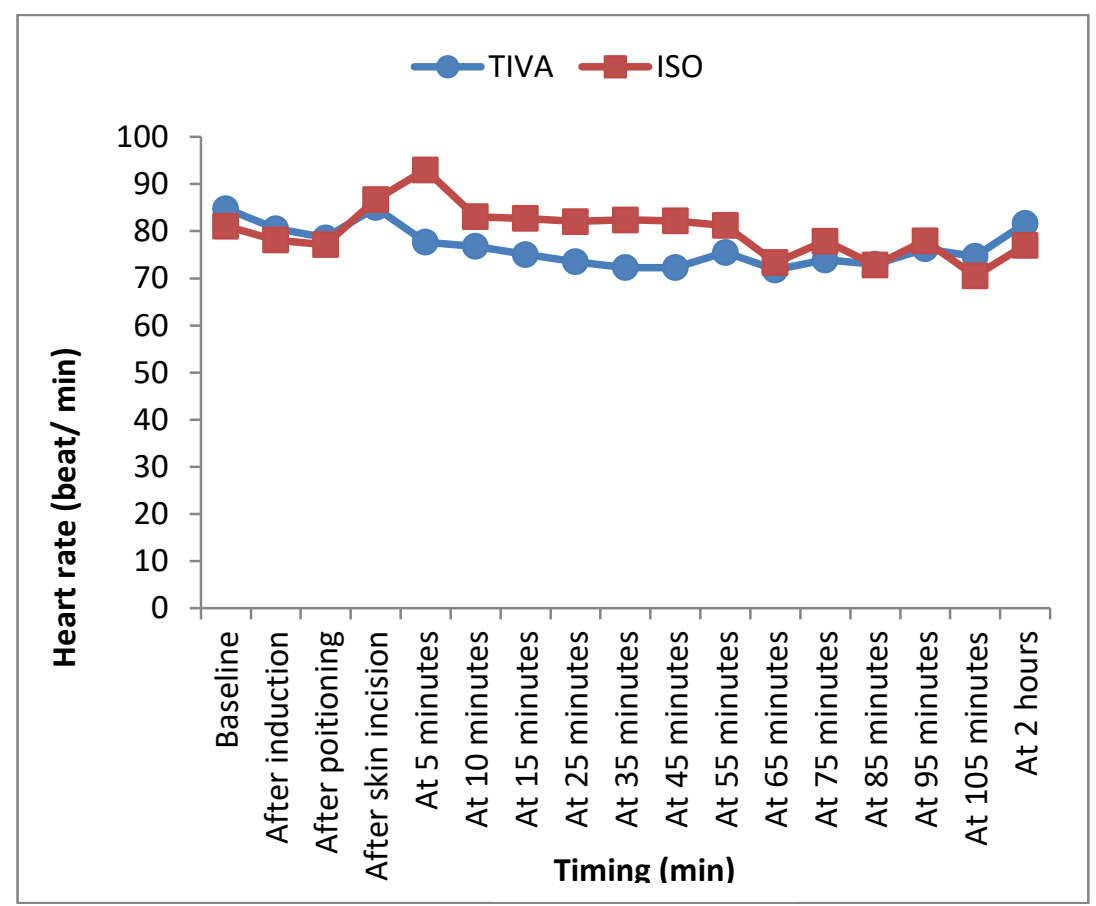

Figure 3. Showing change in heart rate (beat per min) among studied groups over the scheduled time.

TIVA group: total intravenous anesthesia using propofol

Iso group: isoflurane group

Data were expressed as mean \pm Standard deviation (SD)

$\mathrm{t}$ : independent sample $\mathrm{t}$ test

$\mathrm{p}<0.05$ is statistically significant

$\mathrm{p} \leq 0.001$ is highly significant

\section{DISCUSSION}

The study assessed the hemodynamic characteristics and quality of surgical field in spine surgery, comparing total intravenous anesthesia (with propofol) and inhalational anesthesia (with isoflurane).

In this study, there were no statistically significant differences between studied groups regarding age, physical status and BMI. Both groups had comparable numbers of male and females.

Regarding mean blood pressure, the current study show that there were highly statistically significant differences between the studied groups as it less in propofol group than isoflurane group at 5, 10, 15, 25, 55 minutes. These results were in agreement with the study of Mishra et al. ${ }^{[9]}$, they found that Propofol provided for brisk control over blood pressure, maintaining a moderate hypotension, thereby resulting in drier surgical field with less bleeding. Price et al. ${ }^{[10]}$ and Gupta et al. ${ }^{[11]}$ in their study found this fall in SBP, DBP, and MAP to be statistically significant $(\mathrm{P}<0.05)$. After induction, all vitals decreased further this may be attributed to the additive hypotensive effect of propofol group and isoflurane group. While the results of this study disagree with the study of, Saravanan et al. ${ }^{[8]}$ as they concluded that controlled hypotension can be achieved equally and effectively by both isoflurane-based inhalational anesthetic technique and TIVA using propofol in functional endoscopic sinus surgery. The mean $( \pm \mathrm{SD})$ time to achieve the target blood pressure in isoflurane groups was $18( \pm 8)$ minutes and $16( \pm 7)$ minutes in the propofol group. There was no statistical difference $(P=$ $0.66)$ between the two groups with regard to median time in achieving target blood pressure (18-28) min. This difference may be explained by different type of operation (functional endoscopic sinus surgery) than in the current study (spine surgery), and different position of the patient (supine position) than in the current study (prone position). 
This current study show that there was significant differences between the studied groups regarding heart rate values as it was less in propofol group than isoflurane group at 35, 45 and 55minutes. These results were in agreement with the study of Aujla et al. ${ }^{[12]}$, who found that higher doses of isoflurane normally lead to tachycardia, thus less chances of getting controlled hypotension.Isoflurane produces sympathetic activity, mainly beta, as seen from the sustained myocardial contractility, increased heart rate and peripheral vasodilatation. The dose-dependent decrease in systemic arterial pressure is caused by a decrease in total peripheral vascular resistance; ventricular work and myocardial oxygen consumption are decreased. Tachycardia occurring with isoflurane anesthesia may be due to increased beta activity or a baro-receptor mediated reflex may be better preserved in isoflurane anesthesia than with halothane or enflurane [13]. In contrary to the results of this study, Saravanan et al. ${ }^{[8]}$ who revealed that There were no significant differences between the propofol group and isoflurane group in functional endoscopic sinus surgery in terms of heart rate measured at different time intervals. The absence of tachycardia suggests that both the groups experienced adequate depth of anesthesia and analgesia.

This study shows that there was statistically significant difference between the studied groups regarding total blood loss, as it was more in isoflurane group (177.15 \pm 20.79) $\mathrm{ml}$ than propofol group (152.25 \pm 29.11) $\mathrm{ml}$.

These results were in agreement with the study of Marzban et al. ${ }^{[14]}$, who found that the amount of hemorrhage in propofol group was less than isoflurane group and the field condition was better in propofol group than the isoflurane group. There were meaningful differences between average of hemorrhage (propofol group $=155 \mathrm{cc}$, and isoflurane group $=291.3 \mathrm{cc} ; \mathrm{P}=0.003)$. While these results disagree with that of study done by Hasani et al. ${ }^{[15]}$, who found that the total blood loss in the propofol group and isoflurane group was not very great, however isoflurane may provide better control of bleeding than propofol, by decreasing systemic vascular
resistance.This difference may be explained by different type of operation as they compare between propofol-remifentanil and isofluraneremifentanil during endoscopic management of cerebrospinal fluid rhinorrhea . The current study compare between propofol and isoflurane in spine surgery.

The current study show that there were highly significant differences between the studied groups regarding surgical field rating (SFR) at 15, 30, 45, 60, 75, 90 minutes.. Propofol group had better surgical field rating than isoflurane group. These results were in agreement with the study of Mishra et al. ${ }^{[9]}$, who found that the operating surgeons who were blinded to anesthetic procedure, reported superior quality of surgical field with propofol infusion. This may be due to steady state plasma level of propofol achieved by continuous infusion providing relatively low $\mathrm{BP}$, resulting into less blood loss and lesser surgical field congestion. While these results disagree with the study of Saravanan et al. ${ }^{[8]}$, who found that TIVA using propofol offers no significant advantage over isoflurane-based inhalational anesthetic technique in terms of operative conditions and blood loss, as the operative field conditions assessed by the same surgeon were grade 3 and less in the both groups $(P=$ $0.34)$.

This study shows that there were no significant differences between the studied groups regarding $\mathrm{ETCO} 2$ and $\mathrm{SpO} 2$ over time, which agree with the results of Aujla et al. ${ }^{[12]}$.

\section{CONCLUSION}

From the results of this study we concluded that in spine surgery, using TIVA with propofol provides better hypotensive anesthesia, decreases blood loss during surgery and also provides good quality of surgical field as compared to using inhalational anesthesia with isoflurane.

\section{Declaration of interest}

The authors report no conflicts of interest. The authors alone are responsible for the content and writing of the paper.

\section{Funding information}

None declared 


\section{REFERENCES}

1. Szpalski M, Gunzburg R, Weiskopf R.B. Hemostasis in spine surgery. European spine Journal.2005;13:1-3.

2. Boonmak $\mathrm{P}$, Boonmak S, Laopaiboon $\mathrm{M}$ : Deliberate hypotension with propofol under general anesthesia.Cochrane Database of systematic Reviews.2016;10:22-60.

3. Gustavo J.F, Marcio de Moraes, Liogi I.F, et al. Induced hypotension in orthognathuc surgery: a comparative study of 2 pharmacological protocols.Journal of oral and maxillofacial surgery.2008;66:2261-2269.

4. Talmage D.E. Total intravenous anesthesia versus inhalational anesthesia. Journal of Cardiothoracic and Vascular Anesthesia.2015;29:3-9.

5. Feng AY, Kaye AD, Kaye RJ, Belani K, Urman RD. Novel propofol derivatives and implications for anesthesia practice. $\mathrm{J}$ Anesthesia Clinical Pharmacology.2017;33:915.

6. Eger EI, Eisenkraft JB, Weiskopf RB.: The pharmacology of inhaled anesthetics.Seminars in anesthesia,perioperative medicine and pain. 2005;24:89-100.

7. Fromme G.A, Ronald A.M, Allan B.G. Controlled Hypotension for orthognathic surgery. Anesthesia and Analgesia.1986;65:683-686.

8. Saravanan PA, Manickam P, Cherian VT, Thomas S, Kumar K, Jeslin L et al.: Comparison of total intravenous anesthesia and inhalational anesthesia for controlled hypotension in functional endoscopic sinus surgery. Journal of Anesthesia. 2011; 27:328332.

9. Mishra LD, Pradhan SK, Pradhan CS Comparison of propofol based anaesthesia to conventional inhalational general anaesthesia for spine surgery. Journal of Anaesthesiology Clinical Pharmacology. 2011 ;27(1):59-61.

10.Price ML, Walmsley A, Swaine C, Ponte J. Comparison of a total intravenous anaesthetic technique using a propofol infusion, with an inhalational technique using enflurane for day case surgery. Anaesthesia.1988;43:84-87.

11.Gupta A, Stierer T, Zuckerman R, Sakima N, Parker SD, Fleisher LA. Comparison of recovery profile after ambulatory anesthesia with propofol, isoflurane, sevoflurane and desflurane: A systematic review. Anesth Analg.2004;98:632-641.

12. Aujla KS,Kaur M,Gupta R, Singh $\mathrm{S}$, Bhanupreet, Tavleen A study to compare the quality of surgical field using total intravenous anesthesia (with propofol) versus inhalational anesthesia (with isoflurane) for endoscopic sinus surgeries.Anesth Essays Res.2017 ;11:606-610.

13.Ebert J, Muzzi. Sympathetic hyperactivity during isoflurane anesthesia in healthy volunteers: A comparison with desflurane. Anesthesiology.1993;79: 444-453.

14. Marzban S, Haddadi S, Mahmoudi H , Heidarzadeh A, Nemati S, Naderi Nabi B. Comparison of surgical conditions during propofol or isoflurane anesthesia for endoscopic sinus surgery. Anesth Pain Med.2013; 3(2): 234-238.

15.Hassani V ,Alimian M, Farhadi M, Zaman B, Mohseni M. Surgeon satisfaction during Endoscopic management of cerebrospinal fluid Rhinorrhea : A comparison between propofolremifentanil and isoflurane-remifentanil anaesthesia J Minim Invasive Surg Sci.2012;1(2):62-66. 